\title{
ИЗМЕРЕНИЕ ТИПОВ ЛЕСА \\ И ИХ ВЗАИМОСВЯЗЬ С ВОЗРАСТОМ СОСНЯКОВ
}

(по данным J. Ilvessalo из книги А. К. Каяндера о типах лесов Южной Финляндии)

Мазуркин Петр Матвеевич

Д-р техн. наук, проф., академик ЕАЕ, РАЕ и РАЕН

Поволжский государственный технологический университет, г. Йошкар-Ола

\section{MEASUREMENT TYPES OF FORESTS AND THEIR RELATIONSHIP WITH AGE PINE FORESTS}

(according to J. Ilvessalo from A.K. Kayander's book about the woods of the Southern Finland)

Mazurkin Peter Matveevich

Dr. Sci. Sciences, prof., acad. of EAE, PAE and Natural Sciences Volga state University of technology, Yoshkar-Ola

\begin{abstract}
Аннотация По данным из брошюры А. К. Каяндера идентифицированы устойчивые законы и математически доказаны взаимные связи между рангами типов леса и возрастом сосняков. Для возможности моделирования шкала типов леса была дана рангами. Показано, что существующие таблицы хода роста можно отобразить двухчленными формулами, показывающими изменения запаса стволовой древесины сосняков в зависимости от ранга типа леса и возраста древостоя. Еще точнее такие статистические модели будут при использовании не выровненных и не сгруппированных данных измерений древостоев.

Abstract According to the brochure A.K. Kayander identified stable laws and mathematically proven mutual relationship between the ranks of forest types and age of pines. To be able to modeling $\mathrm{c}$ range of forest types were given ranks. It is shown that the existing tables of the growth can display two-term formulas involving changes stem volume pine, depending on rank and type of forest stand age. More precisely such statistical models will be using are not aligned and grouped data measurement stands.
\end{abstract}

Ключевые слова: типы леса, ранговая шкала, возраст, запас, закономерности Keywords: forest types, rank scale, age, stock patterns

Введение. Типизация лесов больше относится к искусству, чем к науке. Она от простой классификации Ilvessalo и А. К. Каяндера [3] в нашей стране превратилась в сложную структуру так называемой динамической типологии [4]. Но схемы Г. Ф. Морозова, В. Н. Сукачева и И. С. Мелехова не дают количественной привязки самих типов как параметров леса.

Поэтому ныне проблема параметризации типов леса может быть разрешена только по известной линейной схеме из [3], но когда типы леса функционально расставлены по местам или рангам от худшего условия произрастания древостоя к лучшему $[7,8]$.

О необходимости выявления закономерностей по таксационным показателям лесных деревьев и древостоев отмечал академик Н. П. Анучин [1, с.11]. 
«Общий результат ряда наблюдений может быть выражен резюмирующим выводом, который в переводе на математический язык называется формулой». Трудности возникают только с так называемыми непараметрическими физическими величинами, то есть с качественными факторами. Например, главным непараметрическим фактором является вид (порода) дерева. Его не могли описать количественными параметрами. Нами предложен способ косвенного измерения породы дерева через базисную плотность древесины [6]. Однако таких сложных показателей мало.

В лесной науке и практике очень часто применяются шкалы с интервальными числовыми значениями, которые составляются по уже имеющимся в пользовании у лесного систематика результатам ранее выполненных измерений (ступень толщины, разряд высоты, класс возраста и пр.). Такие шкалы были созданы только для удобства ручных вычислений. В XXI век информационных технологий от таких шкал нужно категорически отказаться.

Второй вид шкал, широко применяемых в лесном хозяйстве, - это квалиметрические шкалы символьными значениями. Например, проф. М. М. Орлов [12, с.466] всего наметил девять классов бонитета леса. При этом пять классов отведены для часто встречающихся древостоев, и по два крайних класса - для очень высоких и очень низких по бонитету древостоев.

Здесь количественные значения продуктивности по древесине (в Англии применяется натуральная шкала бонитета леса) сгруппированы и помещены в группы с номерами по римским цифрам. Нами кодовая шкала бонитета с арабскими цифрами дана в [6, с.146-148].

По типам леса Ilvessalo и А. К. Каяндер [3] ввели символы по первым буквам названий напочвенного покрова в нормальном спелом древостое. Идея А. К. Каяндера заключается в том, что тип леса и почва являются независимыми факторами. Но она не была доказана.

Цель статьи - проанализировать количественные данные из брошюры А. К. Каяндера [3] и статистическим моделированием идентификацией устойчи- 
вых законов [5-10] математически доказать наличие взаимных связей между рангами типов леса и возрастом сосняков.

Ранговое моделирование. Математическое описание статистической выборки вначале требует определения системы координат. Во многих случаях имеются количественные значения показателя $y$, но только качественные значения объясняющей переменной $x$.

В таких случаях имеются два варианта шкал измерения вдоль оси абсцисс:

1) присвоение мест по убывающим (возрастающим) значениям изучаемого показателя, то есть в порядке $1,2,3, \ldots$;

2) присвоение рангов по убыванию (возрастанию) значений исследуемого показателя, то есть по целочисленной шкале $R=0,1,2,3, \ldots$ ряда натуральных чисел.

Расположение чисел в табличной модели по любому фактору имеет важное методологическое значение, так как сразу же определяет так называемый предпорядок предпочтения.

Главным мотивом упорядочения проф. П. П. Маслов считал необходимость лучшего обозрения статистической выборки $[11$, с.36]: «Эти данные для лучшего обозрения надо прежде всего упорядочить, например расположить в порядке возрастания или убывания». Сам он выбрал путь упорядочения в порядке возрастания [11, с.37]. Но наглядность - не главная черта. Нужно также сущностное наполнение [9] статистической выборки измерений.

Без учета эвристических характеристик всегда происходит «рысканье» или «тремор» в поведении исследователя. Любое планирование эксперимента как некая «вещь» похоже на прибор, сознательно создающий случайности в детерминированном протекании процессов, в нашем случае в поведении сосняков. Парадокс Н. Винера заключается в том, что «хорошая экстраполяция гладкой кривой, по-видимому, требовала применения точного и чувствительного прибора, чем наилучшее возможное предсказание негладкой кривой: в каждом отдельном случае выбор прибора зависел бы от статистической природы предсказываемого явления». По мнению Н. Винера такое противоречие аналогично 
принципу неопределенности Гейзенберга в квантовой механике, т. е. противоречия в положении и количестве движения.

Нужно аксиоматически принять слова Бэкона, что исследователь должен не допрос природе учинять, а внимательно слушать её дыхание и на этой основе получать «зеркальное отображение» поведения природы в виде математических моделей [9, с.40-41].

Предпорядок предпочтения типов леса отметил сам А. К. Каяндер: по Х. Готта (1804 г.) «абсолютно бесплодная почва обозначается 0» [3, с.8]; «Когда классифицируют места произрастания, естественно, ближайшей задачей является стремление к прямой классификации на основе их свойств, на так называемых факторах мест произрастания» [3, с.12].

Ранги типов леса. Введем кодовую шкалу типов леса по рангам $R: 0$ - абсолютно бесплодная почва; 1 - СІT; 2 - СТ; 3 - VT; 4 - MT; 5 - OMT; 6 - ОМаТ и т.д. Расшифровка символов, обозначающих типы леса, подробно дана по содержанию в книге [3]. В таблице 1 дано обилие видов $N_{\text {в }}$ растений [3, с.37].

Таблица 1.

Количество видов

\begin{tabular}{|c|c|c|c|c|c|}
\hline Tип & Ранг & $N_{s}$, & \multicolumn{3}{|c|}{ по модели (1) } \\
\cline { 4 - 6 } леса & $R$ & шт. & $N_{\varepsilon}$ & $\mathcal{E}$ & $\Delta, \%$ \\
\hline OMaT & 6 & 107 & 107,0 & 0,03 & 0,03 \\
\hline OMT & 5 & 105 & 105,1 & $-0,08$ & $-0,08$ \\
\hline MT & 4 & 86 & 86,1 & $-0,07$ & $-0,09$ \\
\hline VT & 3 & 58 & 57,5 & 0,54 & 0,93 \\
\hline CT & 2 & 28 & 28,9 & $-0,92$ & $-3,30$ \\
\hline
\end{tabular}

Количество видов определяется уравнением

$$
N_{6}=8,20681 R^{1,85804} \exp \left(-0,0035172 R^{3,00140}\right),
$$

максимальная относительная погрешность 9,13\%.

Следующим общесистемным фактором является численность пробных площадей по типам леса. Распределение 240 сосняков (табл. 2) иден-

тифицируем дважды:

1) по нормальному закону Гаусса (число $\pi$ скрыто)

$$
N=85,48840 \exp \left(-0,36381(R-2,97083)^{2}\right) .
$$

2) по биотехническому закону [2] в виде формулы из двух законов

$$
N=18,84263 R^{2,40667} \exp \left(-0,087764 R^{2,33533}\right) .
$$

По максимальной относительной погрешности модель (2) в 1,5 раза лучше.

Исходные данные. В таблице 3 [3, с.34-35] четко представлена «конструкция - параметры», а описание функций на эвристическом уровне по типам леса дано в брошюре. 
Пусть вначале тип леса будут независимым от возраста параметром. Такое допущение принято в лесоведении, и они стараются создавать идеально структурированные классифика-

Количество $N$ пробных площадей

Таблица 2.

\begin{tabular}{|c|c|c|c|c|c|c|c|c|}
\hline \multirow{2}{*}{$\begin{array}{l}\text { Тип } \\
\text { леса }\end{array}$} & \multirow{2}{*}{$\begin{array}{c}\text { Ранг } \\
R\end{array}$} & \multirow{2}{*}{\begin{tabular}{|c}
$\hat{N}$, \\
Шт.
\end{tabular}} & \multicolumn{3}{|c|}{ по Гауссу (1) } & \multicolumn{3}{|c|}{ по модели (2) } \\
\hline & & & $N$ & & & & & \\
\hline 8. & 5 & & 10 & & & & & \\
\hline & & & & & & & & \\
\hline $\mathrm{T}$ & & & & & & & & \\
\hline & & & & & & & & \\
\hline CIT & 1 & 13 & 20,8 & 7,81 & 60,05 & 17,3 & $-4,26$ & $-32,7$ \\
\hline
\end{tabular}

ции, хотя это противоречит основному закону Барри Коммонера «всё связано со всем». В следующих статьях опровергнем мнение о независимости типов леса друг от друга. Но пока пусть параметры лесной почвы сведены по А. К. Каяндеру в независимые группы «типы леса», которые в таблице 3 закодированы положительными целыми числами.

Таблица 3.

Запас $V$ деловой древесины

в коре в нормальных сосняках [3, с.34-35], $\mathbf{m}^{3}$

\begin{tabular}{|c|c|c|c|c|c|}
\hline Bозраст & \multicolumn{5}{|c|}{ Ранг типа леса } \\
\cline { 2 - 6 } & 5 & 4 & 3 & 2 & 1 \\
\hline 10 & 19 & 13 & 10 & 7 & - \\
\hline 20 & 70 & 60 & 44 & 24 & 3 \\
\hline 30 & 140 & 135 & 87 & 47 & 10 \\
\hline 40 & 208 & 200 & 134 & 75 & 17 \\
\hline 50 & 279 & 260 & 177 & 104 & 31 \\
\hline 60 & 344 & 313 & 219 & 128 & 46 \\
\hline 70 & 405 & 363 & 262 & 153 & 62 \\
\hline 80 & 458 & 407 & 299 & 178 & 80 \\
\hline 90 & 500 & 443 & 328 & 203 & 98 \\
\hline 100 & 535 & 472 & 351 & 222 & 114 \\
\hline 110 & 560 & 492 & 366 & 240 & 132 \\
\hline 120 & 576 & 503 & 375 & 254 & 148 \\
\hline 130 & - & - & 382 & 266 & 164 \\
\hline 140 & - & - & - & 275 & 180 \\
\hline 150 & - & - & - & 282 & 195 \\
\hline
\end{tabular}

Кроме того, принимаем допущение, что: «В своей динамической типологии леса И. С. Мелехов предлагает уделять основное внимание древостою как основному компоненту (эдификатору) леса и объекту хозяйственного воздействия» [4]. Негласно это давно принято в лесоведении и лесоводстве, но И. С. Мелехов это просто узаконил в науке. Различие в типологиях И. С. Мелехова и А. К. Каяндера заключается в том, что первый рассматривает молодняки после сплошных рубок древостоев, а второй - предложил типы у спелых сосняков.

Методика выявления устойчивых закономерностей в лесной таксации, лесоведении и лесоводстве дана в [2, 5-10]. В любом виде живого вещества оба закона роста и гибели присутствуют совместно и такую совместность мы назвали биотехническим законом. Он проявляется в любых системах, в том числе и из косного вещества, преобразованного живым веществом. Например, Земля много раз была «переработана» своей биосферой и из-за космических катастроф до восьми раз преобразовывалась сама биосфера нашей планеты. 
В итоге любой человек или персонал с техническими устройствами являются носителями биотехнического закона. Как будет показано в других статьях, не исключение здесь и изменение типов леса по кодам и рангам.

Пространственный график запаса древесины по таблице хода роста сосняков Южной Финляндии по состоянию на 1916-1918 гг. показан на рисунке 1.

Поверхность отклика почти идеальная по форме, и это указывает на стремление автора таблицы хода роста к красивой мысленной картине. Она получилась, как известно [3], ручным выравниванием данных измерений по 240 пробным площадям сосняков. Таким образом, группировка в таблице 3 выполнялась так, чтобы ряды возраста были равными по интервалам возраста. Аналогично по мысленной прямой ли-

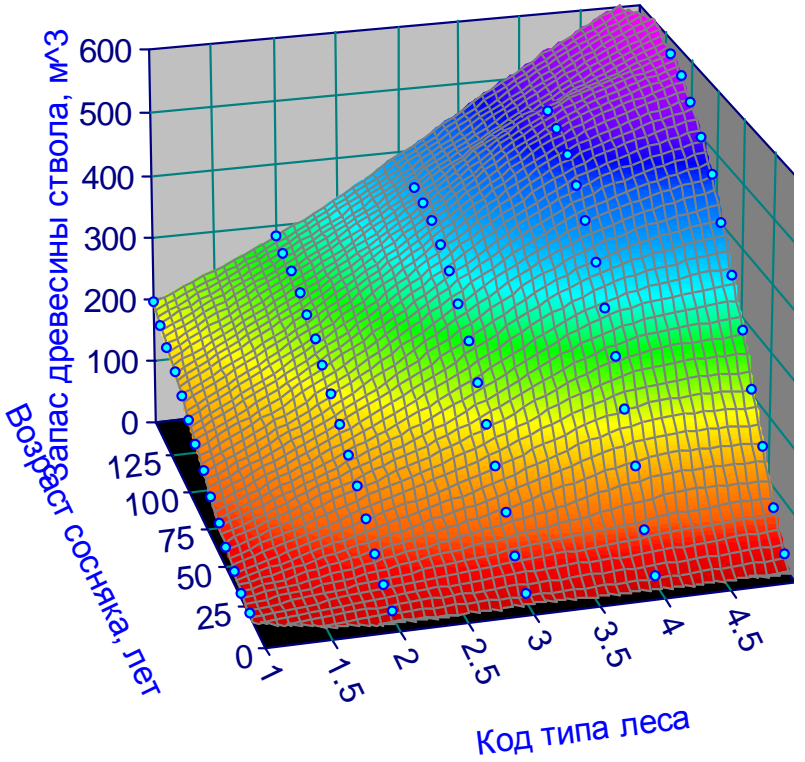

Рисунок 1. Поверхность отклика по данным таблицы 3 нии пытались расставлять свойства лесной почвы по типам леса. Список СIT, CT, VT, МТ и ОМТ почти однозначно переводится в коды 1, 2, 3, 4 и 5.

Вначале выявим однофакторные закономерности типа $V=f(A)$ и $V=f(R)$ по всем 66 значениям (клеткам) из данных таблицы 3.

Влияние возраста на запас. График влияния (рис. 2) имеет уравнение

$$
V=0,0046494 A^{3,06239} \exp (-0,029311 A) .
$$
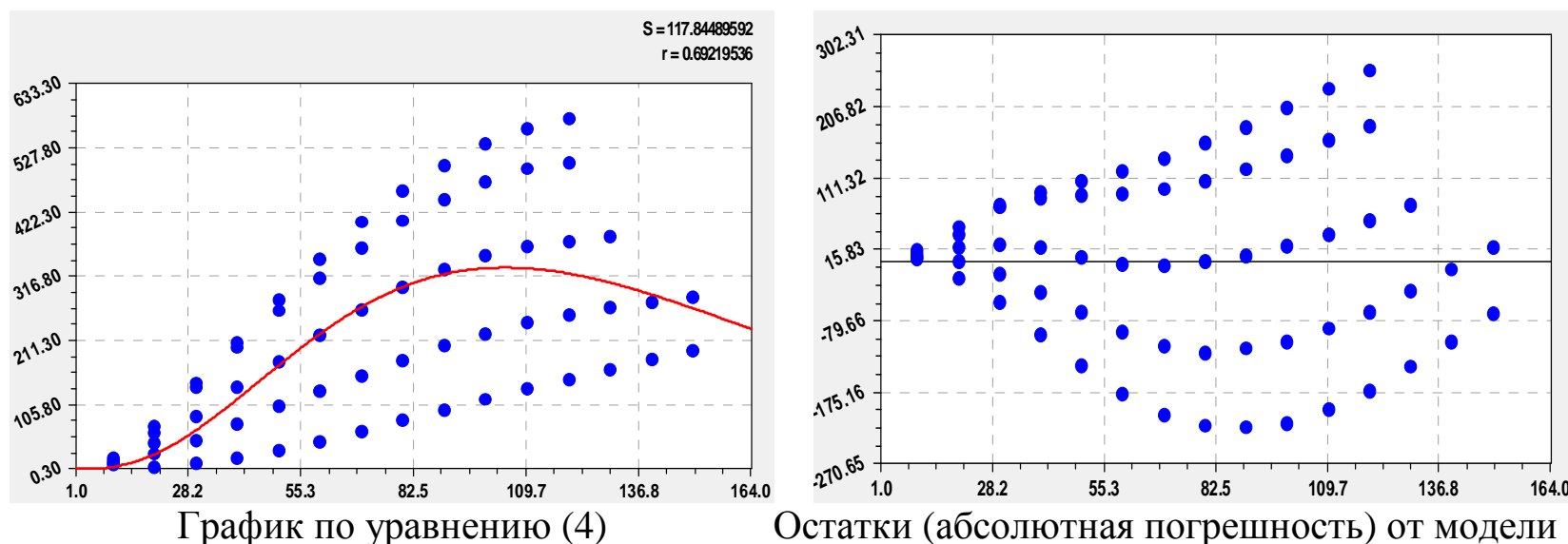

Рисунок 2. Графики влияния возраста 66 типовых сосняков на их запас по стволовой древесине 
Коэффициент корреляции (4) равен 0,6022 и он близок к сильной тесноте связи. Остатки от (4) значительны и это позволит нам ввести дальше влияние второго фактора.

Влияние кода типа леса на запас. Тип леса (рис. 3) влияет по формуле

$$
V=88.34548 R^{0,90463} \exp \left(-1,04879 \cdot 10^{-5} R^{5,70801}\right) .
$$

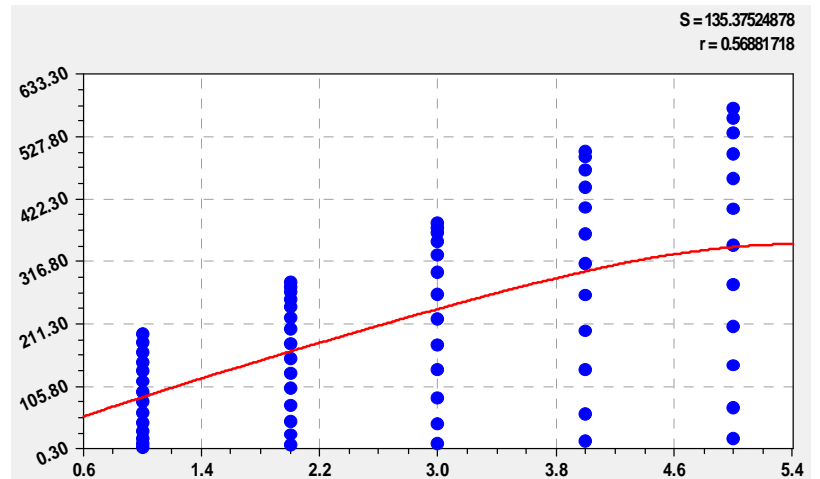

График по уравнению (5)

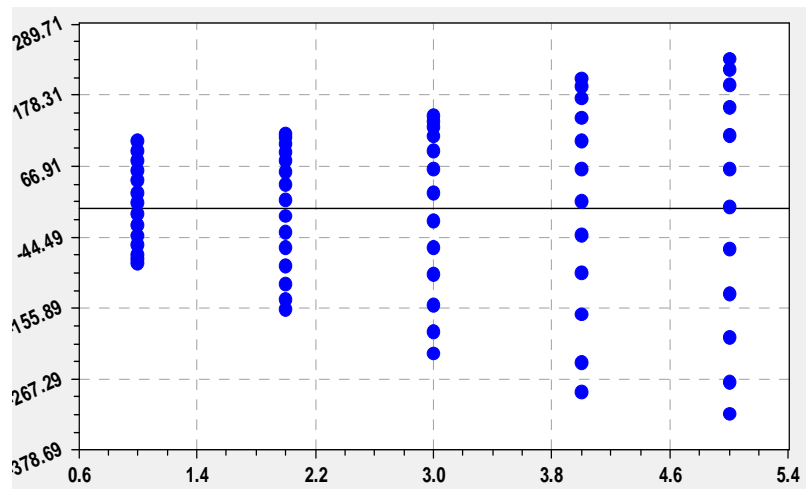

Остатки (абсолютная погрешность) от модели (5)

Рисунок 3. Графики влияния кода типа леса на запас 66 типовых сосняков по стволовой древесине

Коэффициент корреляции равен 0,5688. Поэтому наблюдается средняя теснота связи. Далее выявим двухфакторные биотехнические закономерности.

Запас от возраста и кода типа леса. Остатки от рисунка 2 (рис. 4) имеют:

$$
\begin{gathered}
V=0,0046494 A^{3,06239} \exp (-0,029311 A)+ \\
+82,07056 R^{1,02492} \exp \left(-1,91663 \cdot 10^{-5} R^{5,62174}\right)-227,5656 .
\end{gathered}
$$

Коэффициент корреляции стал равен $0,8887$.

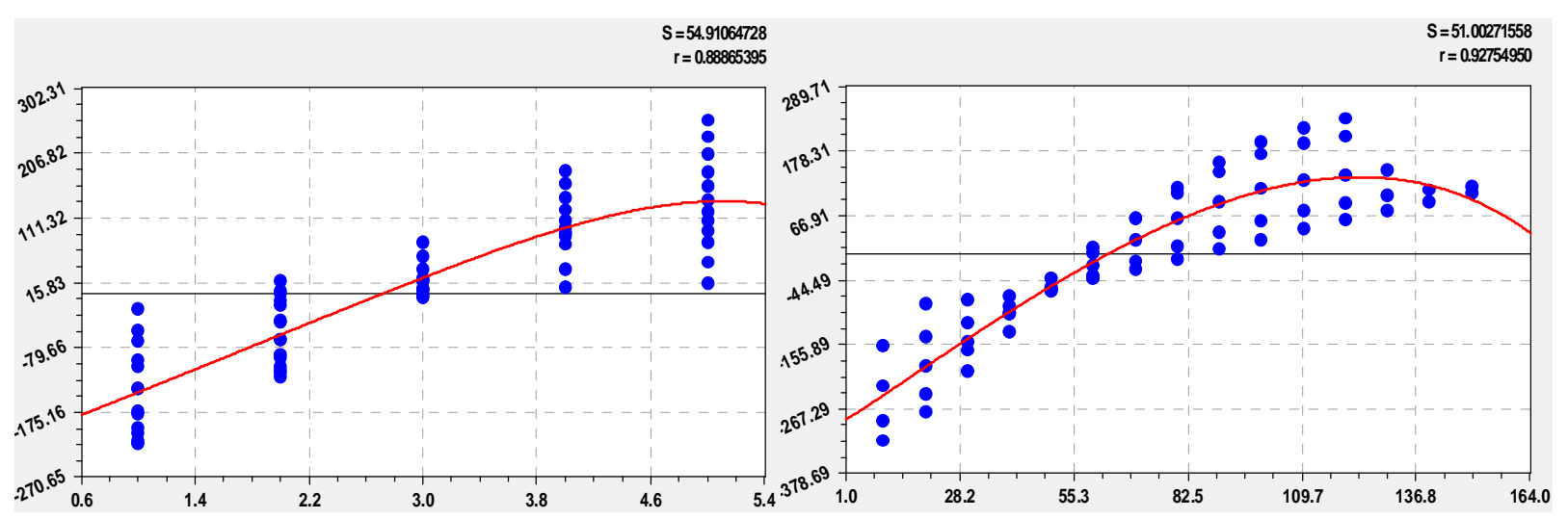

Влияние возраста и кода типа леса по (6) Влияние кода типа леса и возраста по (7)

Рисунок 4. Графики влияния двух факторов на запас древесины у 66 типовых сосняков

Запас от кода типа леса и возраста. Остатки от рисунка 3 (рис. 4) дают трехчленную модель вида

$$
V=88.34548 R^{0,90463} \exp \left(-1,04879 \cdot 10^{-5} R^{5,70801}\right)-
$$




$$
-289,3507 \exp \left(0,0028121 A^{1,22773}\right)+4,84580 A^{1,09636} .
$$

Коэффициент корреляции равен 0,9275 и модель (7) перевелась на уровень адекватности по сильнейшей тесноте связи >0,9. В сравнении с (6) остатки (7) стали намного меньше.

Тогда формула (7) с высокой адекватностью идентифицирует данные таблицы 3 и поэтому она вполне может заменить громоздкие и неудобные в пользовании таблицы хода роста. Но в ближайшем будущем нужно идентифицировать формулу типа (7) по фактически измеренным параметрам древостоя и почвы на каждой пробной площади изучаемого леса. В итоге не будет необходимости в выравнивании и группировке первичных исходных данных.

Далее рассмотрим взаимные влияния возраста и кода типа леса.

Влияние кода типа леса на возраст древостоя. Получена двухчленная формула с коэффициентом корреляции всего 0,2072. Это - слабая факторная связь, поэтому неадекватна.

Влияние возраста на код типа леса. Оно (рис. 5) определяется формулой $R=53,28981 \exp \left(-2,73713 A^{0,011082}\right)-8,85190 \cdot 10^{-126} A^{65,79688} \exp \left(-0,0098681 A^{1,66445}\right)$. (8)

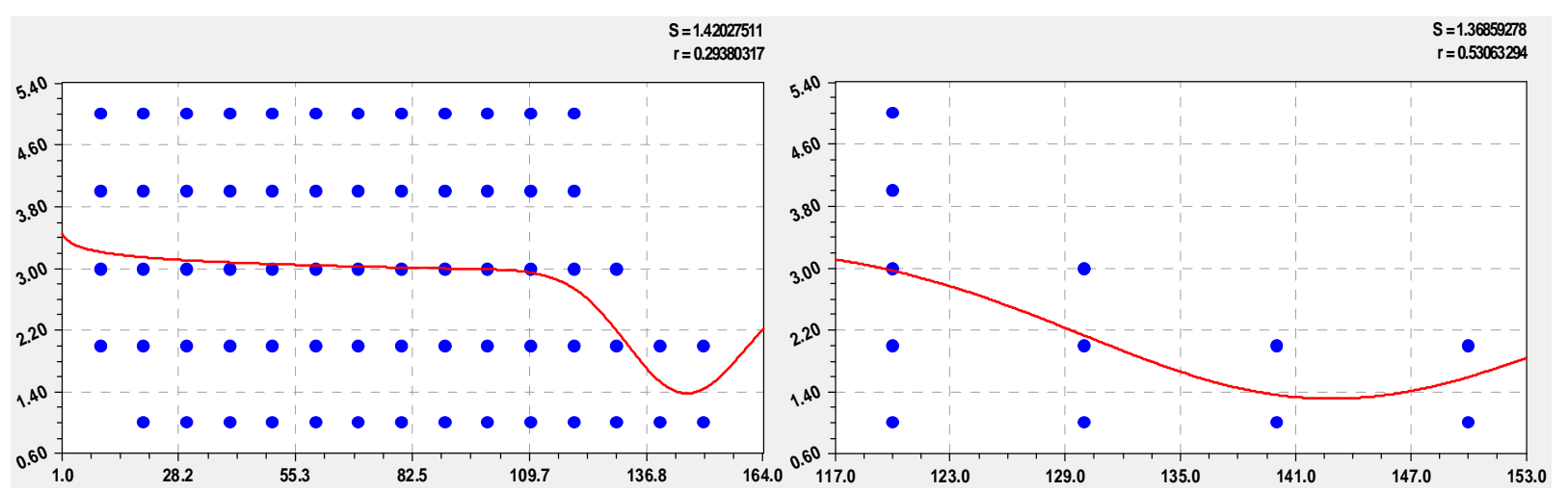

Интервал возраста древостоя 10-150 лет Интервал возраста древостоя 120-150 лет Рисунок 5. Графики влияния возраста древостоя на код тип леса у 66 типовых сосняков

Из формулы (8) видно, что при условии $A=0$, то есть в момент появления лесных деревьев и древостоев, тип леса должен быть с очень высоким кодом около 53. Это означает, что для массового появления всходов сосен нужна высокоплодородная лесная почва.

Влияние возраста не менее 80 лет, когда в СССР академик Н. П. Анучин разрешил сплошные рубки в Европейской части страны с 81 года (вместо 101 
года) возраста сосняков на код типа леса проявляется, при коэффициенте корреляции 0,3798, уравнением

$$
R_{A=80-150}=3,05366-3,27167 \cdot 10^{-109} A^{57,06240} \exp \left(-0,0085799 A^{1,66281}\right) .
$$

На границе предельного возраста 120 лет получено (рис. 5) выражение

$$
R_{A=120-150}=3,34403-1,09554 \cdot 10^{-135} A^{71,14703} \exp \left(-0,0084726 A^{1,71265}\right) .
$$

Элиминирование начального возраста до 50 лет у так называемых «хозяйственных сосняков» приводит к превращению закона экспоненциальной гибели из формулы (8) к постоянному члену в формулах (9) и (10). От 80 до 120 лет средний тип леса возрастет в 3,344 / 3,054 $\approx 1,095$ раза или на 9,5\%. Таким образом, приспевающий сосняк улучшает среду своего обитания, то есть между древостоем и почвой имеются сложные взаимные связи.

Динамика левой границы возраста. Из графиков на рисунке 5 видно, что с сокращением интервала эксплуатационного возраста адекватность статистической модели повышается (табл. 4). Это указывает на то, что приспевающие сосняки постепенно меняют тип леса, который был в период роста молодняка. Тогда получается, что динамическая типология на количественном уровне взаимных связей между параметрами древостоя и его почвы характерна не только в молодняках по И. С. Мелехову [4], но и в спелых сосняках по статической типологии Ilvessalo и А. К. Каяндера [3].

таблица 4 Этот вывод подтверждается тем, что изменение коДинамика адекватности

\begin{tabular}{|c|c|}
\hline $\begin{array}{c}\text { Возраст } \\
A_{1}, \text { лет }\end{array}$ & $\begin{array}{c}\text { Коэфф. } \\
\text { коррел. } r\end{array}$ \\
\hline 10 & 0.2938 \\
\hline 80 & 0.3798 \\
\hline 90 & 0.4083 \\
\hline 100 & 0.4407 \\
\hline 110 & 0.4810 \\
\hline 120 & 0.5306 \\
\hline
\end{tabular}
эффициента корреляции от левой границы возраста $A_{1}$ определилось, при адекватности по коэффициенту корреляции 0,9994, уравнением вида

$$
r=0,28812 \exp \left(7,62146 \cdot 10^{-5} A_{1}^{1,87549}\right),
$$

где $A_{1}$ - возраст начала таблицы хода роста, лет.

Таким образом, идеальной типологии лесов не существует.

Поэтому гипотеза А. К. Каяндера о независимости типов древостоев от типов лесной почвы, по мере приближения возраста сосняков к технической и финансовой спелости, дает растущую погрешность. 
Заключение. Возрастная структура сосняков Южной Финляндии по состоянию на 1916-1918 гг. в книге [3] определена в данных таблицы 3 с разными правыми границами 150, 130 и 120 лет. При этом период возраста 50-120 лет это хозяйственный лес и по терминологии Г. Ф. Морозова в его учении о лесе.

Но тогда таблица 3 является явно неполной классификацией по предельному возрасту сосняков, так как не учитываются биологически спелые и климаксовые типы древостоев. поэтому обособление таблицы хода роста сосняков только по технической и финансовой спелости является нарушением основных принципов и самого «символа лесоводственной веры», причем из количественно противоречивого учения о лесе Г. Ф. Морозова.

Финские учёные, как видно из вышеприведенных устойчивых биотехнических закономерностей, также не восприняли практически в лесном хозяйстве идеи русского космизма и символ лесоводственной веры, а ограничились только хозяйственными сосняками.

С увеличением возраста древостоя тип леса становится зависимым от возрастного параметра сосняка. Поэтому классификация А. К. Каяндера типов леса по напочвенному покрову в спелых нормальных сосняках имеет значимую погрешность, прежде всего, из-за разных правых границ возраста в 150, 130 и 120 лет. Ныне сосняки стали «ненормальными».

Существующие таблицы хода роста сосняков вполне можно отобразить двухчленными формулами, показывающими изменения запаса стволовой древесины сосняков в зависимости от кода типа леса и возраста древостоя. Еще точнее такие статистические модели будут при использовании не выровненных и не группированных данных измерений древостоев.

\section{Литература:}

1. Анучин Н.П. Лесная таксация: учебник. М.: Лесная пром-сть, 1982. 522 с.

2. Верхунов П.М., Мазуркин П.М. Таксация древесного ствола лесных насаждений: учеб. пос. Йошкар-Ола: МарГТУ, 1999. 72 с.

3. Каяндер А.К. І. Сущность и значение типов леса. II. Различие в учениях о типах леса (Каяндера, Морозова и Сукачева). М.: Гослестехиздат, 1933. 50 с. 
4. Концепция динамической типологии И.С. Мелехова (часть 1) // http://allyears.ru/ lesovedenie/1177-koncepciya-dinamicheskoy-tipologii-i-smelehova-chast-1.html (дата обращения 16.03.2013).

5. Мазуркин П.М. Дендрометрия. Статистическое древоведение: учеб. пос. Часть 1. Йошкар-Ола: МарГТУ, 2003. 308 с.

6. Мазуркин П.М. Дендрометрия. Статистическое древоведение: учеб. пос. Часть 2. Йошкар-Ола: МарГТУ, 2003. 205 с.

7. Мазуркин П.М. Динамика запаса сосняков по типам леса (по данным J. Ilvessalo из книги А.К. Каяндера о лесах Южной Финляндии) // II Междунар. научно-практ. конф. «Актуальные вопросы науки и хозяйства: новые вызовы и решения». СПб.: Общественная научная организация «Наука и хозяйство», 2527.09.2014. № 2. 2014. С. 38-47.

8. Мазуркин П.М. Поведение сосняков ккак эргатической системы леса (по данным J. Ilvessalo из книги А.К. Каяндера о лесах Южной Финляндии) // III Междунар. научно-практ. конф. «Актуальные вопросы науки и хозяйства: новые вызовы и решения». СПб.: Общественная научная организация «Наука и хозяйство». № 3. 2014. С. 58-64.

9. Мазуркин П.М. Статистическое моделирование. эвристико-математический подход. Йошкар-Ола: МарГТУ, 2001. 100 с.

10. Мазуркин П.М., Филонов А.С. Математическое моделирование. Идентификация однофакторных статистических закономерностей: учеб. пос. Йошкар-Ола: МарГТУ, 2006. 292 с.

11. Маслов П.П. Статистика: учеб. пос. М.: Изд-во ВПШ и АОН, 1958. 264 с.

12. Орлов М.М. Лесоустройство. Т.1. Элементы лесного хозяйства. Л., 1927. $428 \mathrm{c}$. 